\title{
Panton-Valentine leukocidin-positive meticillin-resistant Staphylococcus aureus in the community in Hong Kong
}

Meticillin-resistant Staphylococcus aureus (MRSA) strains producing the potent tissue necrotizing toxin Panton-Valentine leukocidin (PVL) encoded by the $p v l$ gene, and harbouring SCCmec type IV or V elements, have been implicated as being associated with MRSA infection acquired in the community setting (Vandenesch et al., 2003; Boyle-Vavra \& Daum, 2007). Since the 1990s, community-associated (CA)-MRSA infections have shown a steady increase, and are becoming a significant public-health concern. PVLpositive MRSA isolates have been shown to have distinct genetic backgrounds in different areas, for instance, multilocus sequence typing (MLST) types ST80, ST8 and ST59 were found in the major clones in Europe, USA and Taiwan, respectively (Vandenesch et al., 2003; Tristan et al., 2007; Chen et al., 2005).

In Hong Kong, CA-MRSA infection is a notifiable disease, defined by clinical and epidemiological criteria (Millar et al., 2007), together with molecular characterization of the strain, as belonging to SCCmec type IV or V, and being pvlpositive (CHP, 2008). In an attempt to understand the characteristics and epidemiology of $p v l$-positive MRSA strains in the community in Hong Kong, we characterized 140 CA-MRSA strains isolated in 2006. Our laboratory is a diagnostic and public health laboratory processing clinical specimens from outpatients and hospital inpatients from both the public and private sector. We also serve as a referral centre for characterization of isolates from other laboratories. For any isolate suspected to be CA-MRSA based on clinical and epidemiological grounds, investigations undertaken included antibiogram determination by the disc diffusion method (CLSI, 2005), SCCmec typing (Okuma et al., 2002; Ito et al., 2004) and pvl PCR (Lina et al., 1999). Isolates found to be $p v l$-positive were further subjected to molecular typing studies, including spa typing (Shopsin et al., 1999) using the Ridom SpaServer, MLST (Enright et al., 2000) and PFGE (McDougal et al., 2003).

One hundred and forty putative CA-MRSA isolates from unique patients were examined during 2006. Forty-two isolates (30\%) were found to carry $p v l$. Among these, SCCmec $\mathrm{IV}$ and $\mathrm{V}$ elements were found in 30 $(71.4 \%)$ and $12(28.6 \%)$ isolates, respectively; no other SCCmec element was found in this collection (Table 1). This is in accordance with other reports (Tristan et al., 2007; Boyle-Vavra \& Daum, 2007) that $p v l$ carriage is much more frequently associated with SCCmec types IV and V than other types (I, II or III) in S. aureus. In Hong Kong, pvl-positive SCCmec type $\mathrm{V}$ isolates have been reported in five MRSA strains (Ho et al., 2007). Our results confirmed the previous findings at an extended scale.

The $42 p v l$-positive MRSA strains were mainly recovered from skin and soft tissue specimens $(88.1 \%)$, followed by blood culture $(7.1 \%)$, joint aspirate $(2.4 \%)$ and eye $(2.4 \%)$ specimens. As for the $98 \mathrm{pvl}$ negative MRSA strains, their sites of origin were skin and soft tissue specimens (46.9\%), followed by sputum $(25.5 \%)$, urine $(8.2 \%)$, blood culture $(6.1 \%)$ and other site specimens (13.2\%). PVLpositive MRSA is notoriously associated with skin and soft tissue infection (SSTI). Holmes et al. (2005) reported that the majority (24\%) of pvl-positive S. aureus isolates were linked with SSTI in the UK. A relatively high percentage $(44.6 \%)$ of $p v l$ carriage was also seen among the 83 MRSA isolates from soft tissue specimens examined in our study. Our findings showed that SSTI constituted the majority of cases where $p v l$-positive MRSA was isolated $(88.1 \%)$, while the proportion was only $46.9 \%$ among $p v l$-negative isolates $(P<0.0001)$. These findings from Hong Kong are thus consistent with reports from the literature.

All $42 p v l$-positive $S$. aureus were confirmed to be resistant to $\beta$-lactam antibiotics. Resistance to erythromycin and clindamycin was present in $42.9 \%$ (18/42). In addition, 13 isolates were resistant to tetracycline $(31 \%)$ and 9 to chloramphenicol $(21.4 \%)$. Resistance to ciprofloxacin (3/42), co-trimoxazole (2/ $42)$, rifampicin (1/42) and gentamicin (1/ 42) were less common. Eighteen isolates $(42.9 \%)$ were resistant to two or more non- $\beta$-lactam agents and seven $(16.7 \%)$ were resistant to four or more, whilst one isolate was resistant to five non- $\beta$-lactam agents (Table 1). Some studies have suggested that antibiotic resistance in SCCmec IV or V isolates was often limited to resistance to $\beta$-lactams (Takano et al., 2007). However, multiple non- $\beta$-lactam antimicrobial resistance phenotypes were found in our SCCmec type V isolates, and all of these strains were resistant to at least two, to a maximum of four, non- $\beta$-lactam drugs. These data are in line with reports from other localities (Chen et al., 2005; Coombs et al., 2006). In addition, three of our strains were resistant to ciprofloxacin, and susceptibility to fluoroquinolones as a marker for recognizing putative CA-pvlpositive MRSA strains may be unreliable (Millar et al., 2007). These findings further highlight the importance to public health and the clinical importance of $p v l$-positive MRSA.

Among the 42 strains, 5 MLST types, 5 PFGE types (with $80 \%$ similarity cut-off) and 11 spa types were resolved (Table 1, Fig. 1). The most prevalent MLST types were ST30 and ST59, shared by $22(52.4 \%)$ and $15(35.7 \%)$ isolates, respectively. Further expanding on a published report by Ho et al. (2007), our study showed that the predominant CA-MRSA clones in Hong Kong possessed the genetic background ST30-IV. Our pvl-positive MRSA isolates were segregated by PFGE into 5 clusters, with 2 predominant clusters, A and E, comprising 21 and 17 strains, respectively (Fig. 1). The majority of the isolates were thus shown to be genetically related. Within PFGE group A, 
Table 1. Genotypic and phenotypic characterization of 42 pvl-positive MRSA from Hong Kong

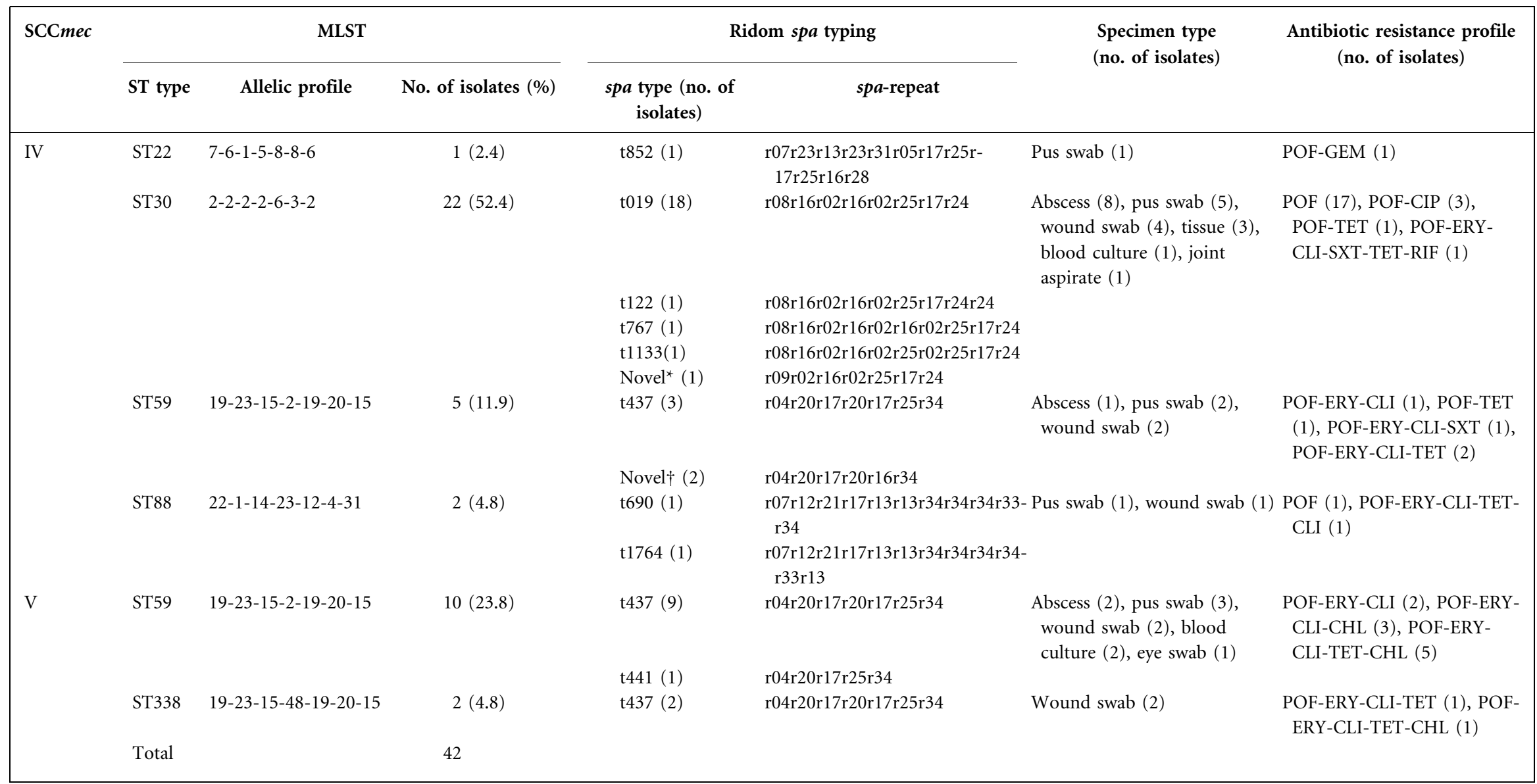

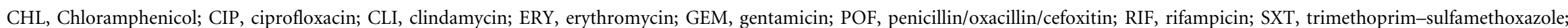
TET, tetracycline.

${ }^{\star}$ Registered as $\mathrm{t} 3382$.

$\dagger$ Registered as $\mathbf{t} 3385$. 
$\underline{\text { Isolate }}$

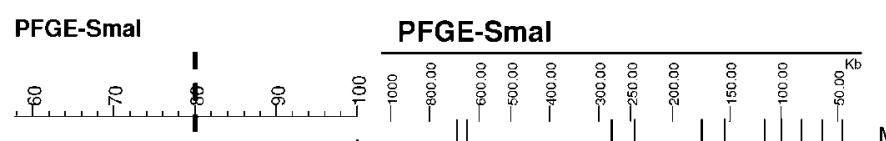

M06-4380334 M06-4380350 33

M06-4340027 40

M06-4380001 1

M06-4380021 3

M06-4380039 5

M06-4380071 6

M06-4380074 8

M06-4380113 11

M06-4380123 13

M06-4380129 14

M06-4380132 15

M06-4380150 16

M06-4380151 17

M06-4380234 21

M06-4380249

M06-4380290 24

M06-4380309 28

M06-4340011 38

M06-4340042 42

M06-4930152 10

M06-4380015

M06-4380072 7

M06-4380373 35

M06-4340007

M06-4380329 30

M06-4380339 32

M06-4340003 36

M06-4380089 9

M06-4930284 19

M06-4380286 23

M06-4380291 25

M06-4380292 26

M06-4380368 34

M06-4380308 27

M06-4380034 4

M06-4380234 29

M06-4380116 12

M06-4380181 18

M06-4930380 20

M06-4340028 41

M06-4340012 39
$\begin{array}{llll}A & \mathrm{t} 767 & 30 & \text { IV }\end{array}$

A $1019 \quad 30 \quad$ IV

$\begin{array}{llll}\text { A } & \mathrm{t} 122 & 30 & \text { IV }\end{array}$

$\begin{array}{llll}A & \mathrm{t} 1133 & 30 & \text { IV }\end{array}$

$\begin{array}{llll}\text { A } & \text { t019 } & 30 & \text { IV }\end{array}$

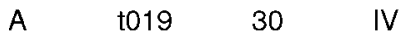

$\begin{array}{llll}\text { A } & 1019 & 30 & \text { IV }\end{array}$

$\begin{array}{llll}\text { A } & 1019 & 30 & \text { IV }\end{array}$

$\begin{array}{llll}\text { A } & 1019 & 30 & \text { IV }\end{array}$

A $1019 \quad 30 \quad$ IV

A $1019 \quad 30$ IV

A $1019 \quad 30 \quad$ IV

$\begin{array}{llll}\text { A } & 1019 & 30 & \text { IV }\end{array}$

$\begin{array}{llll}\text { A } & \text { t019 } & 30 & \text { IV }\end{array}$

$\begin{array}{llll}\text { A } & \text { t019 } & 30 & \text { IV }\end{array}$

$\begin{array}{llll}\text { A } & \text { t019 } & 30 & \text { IV }\end{array}$

$\begin{array}{llll}\text { A } & \text { t019 } & 30 & \text { IV }\end{array}$

$\begin{array}{llll}\text { A } & 1019 \quad 30 \quad \text { IV }\end{array}$

$\begin{array}{llll}\text { A } & \text { t019 } & 30 & \text { IV }\end{array}$

A $1019 \quad 30 \quad$ IV

$\begin{array}{llll}\text { A } & \text { t019 } & 30 & \text { IV }\end{array}$

$\begin{array}{llll}B & \mathrm{H} 3382 & 30 & \text { IV }\end{array}$

$\begin{array}{llll}C & \mathrm{t} 1764 \quad 88 & \text { IV }\end{array}$

C $\quad 1690 \quad 88$ IV

$\begin{array}{llll}D & \mathrm{t} 852 & 22 & \text { IV }\end{array}$

$\begin{array}{llll}\text { E } & 1437 & 59 & \mathrm{~V}\end{array}$

$\begin{array}{llll}E & \mathrm{t} 437 & 59 & \mathrm{~V}\end{array}$

$\begin{array}{llll}E & \mathrm{t} 437 & 59 & \mathrm{~V}\end{array}$

$\begin{array}{llll}E & \mathrm{t} 437 & 59 & \mathrm{~V}\end{array}$

$\begin{array}{llll}E & \mathrm{t} 437 & 59 \quad \mathrm{~V}\end{array}$

$\begin{array}{llll}E & 1437 & 59 \quad \mathrm{~V}\end{array}$

$\begin{array}{llll}E & 1437 & 59 & V\end{array}$

$\begin{array}{llll}E & 1437 & 59 \quad \mathrm{~V}\end{array}$

$\begin{array}{llll} & 1441 & 59 & V\end{array}$

$\begin{array}{llll}E & \mathrm{t} 437 & 338 & \mathrm{~V}\end{array}$

$\begin{array}{llll}E & \mathrm{t} 437 & 59 & \mathrm{~V}\end{array}$

$\begin{array}{llll}E & \mathrm{t} 437 & 338 \quad \mathrm{~V}\end{array}$

E $\quad \mathrm{t} 437 \quad 59 \quad$ IV

E $\quad$ t3385 59 IV

E $\quad 13385 \quad 59 \quad$ IV

$\begin{array}{lllll}\text { E } & 1437 & 59 & \text { IV }\end{array}$

$\begin{array}{llll}\text { E } & \mathrm{t} 437 & 59 & \text { IV }\end{array}$

Fig. 1. PFGE patterns and phylogenetic tree of $42 \mathrm{pvl}$-positive MRSA isolates from Hong Kong. 
all of the strains had an ST30-IV background, while PFGE group E strains were mainly of ST59.

The spa types t019 and t437 were found in $18(42.9 \%)$ and $14(33.3 \%)$ isolates, respectively, and 2 novel spa types, $\mathrm{t} 3382$ and $\mathrm{t} 3385$ were detected in this study. Our results demonstrated that the two dominant spa types t019 and t437 were associated with ST30 and ST59, respectively. These MLST and spa-type associations have been reported in Belgium and the Netherlands as well (Denis et al., 2005; Huijsdens et al., 2006). In addition, five distinct spa types were resolved for the strains belonging to ST30, three distinct types for ST59 and two for ST88 (Table 1). Overall, spa typing was more discriminatory than MLST, a finding that is in agreement with published studies (Strommenger et al., 2006). Among the molecular methods described for typing, MRSA, spa typing and MLST are increasingly favoured over PFGE because their results can easily be transferred, exchanged and compared between different laboratories. In general, genetically closely related spa types were grouped together to form a 'lineage', and the result of spa typing at lineage level appeared concordant with MLST and PFGE, implying that this typing method is suitable in both outbreak investigations and long-term population studies for MRSA strains.

In conclusion, $p v l$-positive putative CAMRSA strains in Hong Kong belonged to SCCmec types IV and V, and were mainly associated with SSTIs. Antimicrobial resistance to various groups of agents, including fluoroquinolones, was not uncommon. Most strains belonged to ST30 and ST59, and exhibited spa type t019 and t0437, respectively. Continued monitoring of the epidemiology of such strains is important to provide a basis for control measures and an evaluation of their effectiveness.

\section{Terence Kin Man Cheung, Yiu Wai Chu, Man Yu Chu, Vivien Yee Man Tsang and Janice Yee Chi Lo}

Microbiology Division, Public Health Laboratory Services Branch, Centre for Health Protection, Department of Health, Hong Kong SAR
Correspondence: Janice Yee Chi Lo (janicelo@dh.gov.hk)

Boyle-Vavra, S. \& Daum, R. S. (2007). Community-acquired methicillin-resistant Staphylococcus aureus: the role of PantonValentine leukocidin. Lab Invest 87, 3-9.

CHP (2008). Communicable Disease Surveillance Case Definitions. Hong Kong: Centre for Health Protection. Published online 28 July 2008. https://ceno.chp.gov.hk/casedef/casedef.pdf

Chen, F.-J., Lauderdale, T.-L., Huang, I.-W., Lo, H.-J., Lai, J.-F., Wang, H.-Y., Shiau, Y.-R., Chen, P.-C., Ito, T. \& Hiramitsu, K. (2005). Methicillinresistant Staphylococcus aureus in Taiwan. Emerg Infect Dis 11, 1761-1763.

CLSI (2005). Performance Standards for Antimicrobial Susceptibility Testing, 15th informational supplement, approved standard MS100-S15. Wayne, PA: Clinical and Laboratory Standards Institute.

Coombs, G. W., Pearson, J. C., O'Brien, F. G., Murray, R. J., Grubb, W. B. \& Christiansen, K. J. (2006). Methicillin-resistant Staphylococcus aureus clones, Western Australia. Emerg Infect Dis 12, 241-247.

Denis, O., Deplano, A., De Beenhouwer, $H_{\text {., }}$ Hallin, M., Huysmans, G., Garrino, M. G., Glupczynski, Y., Malaviolle, X., Vergison, A. \& Struelens, M. J. (2005). Polyclonal emergence and importation of community-acquired methicillin-resistant Staphylococcus aureus strains harbouring Panton-Valentine leucocidin genes in Belgium. J Antimicrob Chemother 56, 1103-1106.

Enright, M. C., Day, N. P., Davies, C. E., Peacock, S. J. \& Spratt, B. G. (2000). Multilocus sequence typing for characterization of methicillin-resistant and methicillin-susceptible clones of Staphylococcus aureus. J Clin Microbiol 38, 1008-1015.

Ho, P. L., Cheung, C., Mak, G. C., Tse, C. W., Ng, T. K., Cheung, C. H., Que, T. L., Lam, R., Lai, R. W. \& other authors (2007). Molecular epidemiology and household transmission of community-associated methicillin-resistant Staphylococcus aureus in Hong Kong. Diagn Microbiol Infect Dis 57, 145-151.

Holmes, A., Ganner, M., McGuane, S., Pitt, T. L., Cookson, B. D. \& Kearns, A. M. (2005).

Staphylococcus aureus isolates carrying PantonValentine leucocidin genes in England and Wales: frequency, characterization, and association with clinical disease. J Clin Microbiol 43, 2384-2390.

Huijsdens, X. W., van Santen-Verheuvel, M. G., Spalburg, E., Heck, M. E., Pluister, G. N., Eijkelkamp, B. A., de Neeling, A. J. \& Wannet, W. J. (2006). Multiple cases of familial transmission of community-acquired methicillin-resistant Staphylococcus aureus. J Clin Microbiol 44, 2994-2996.
Ito, T., Ma, X. X., Takeuchi, F., Okuma, K., Yuzawa, H. \& Hiramatsu, K. (2004). Novel type $\mathrm{V}$ staphylococcal cassette chromosome mec driven by a novel cassette chromosome recombinase, ccrC. Antimicrob Agents Chemother 48, 2637-2651.

Lina, G., Piémont, Y., Godail-Gamot, F., Bes, M., Peter, M. O., Gauduchon, V., Vandenesch, F. \& Etienne, J. (1999). Involvement of PantonValentine leukocidin-producing Staphylococcus aureus in primary skin infections and pneumonia. Clin Infect Dis 29, 1128-1132.

McDougal, L. K., Steward, C. D., Killgore, G. E., Chaitram, J. M., McAllister, S. K. \& Tenover, F. C. (2003). Pulsed-field gel electrophoresis typing of oxacillin-resistant Staphylococcus aureus isolates from the United States: establishing a national database. J Clin Microbiol 41, 5113-5120.

Millar, B. C., Loughrey, A., Elborn, J. S. \& Moore, J. E. (2007). Proposed definitions of community-associated meticillin-resistant Staphylococcus aureus (CA-MRSA). J Hosp Infect 67, 109-113.

Okuma, K., Iwakawa, K., Turnidge, J. D., Grubb, W. B., Bell, J. M., O'Brien, F. G., Coombs, G. W., Pearman, J. W., Tenover, F. C. \& other authors (2002). Dissemination of new methicillinresistant Staphylococcus aureus clones in the community. J Clin Microbiol 40, 4289-4294.

Shopsin, B., Gomez, M., Montgomery, S. O., Smith, D. H., Waddington, M., Dodge, D. E., Bost, D. A., Riehman, M., Naidich, S. \& Kreiswirth, B. N. (1999). Evaluation of protein A gene polymorphic region DNA sequencing for typing of Staphylococcus aureus strains. J Clin Microbiol 37, 3556-3563.

Strommenger, B., Kettlitz, C., Weniger, T., Harmsen, D., Friedrich, A. W. \& Witte, W. (2006). Assignment of Staphylococcus isolates to groups by spa typing, SmaI macrorestriction analysis, and multilocus sequence typing. J Clin Microbiol 44, 2533-2540.

Takano, T., Saito, K., Teng, L. J. \& Yamamoto, T. (2007). Spread of community-acquired methicillin-resistant Staphylococcus aureus (MRSA) in hospitals in Taipei, Taiwan in 2005, and comparison of its drug resistance with previous hospital-acquired MRSA. Microbiol Immunol 51, 627-632.

Tristan, A., Bes, M., Meugnier, H., Lina, G., Bozdogan, B., Courvalin, P., Reverdy, M. E., Enright, M. C., Vandenesch, F. \& Etienne, J. (2007). Global distribution of Panton-Valentine leukocidin-positive methicillin-resistant Staphylococcus aureus, 2006. Emerg Infect Dis 13, 594-600.

Vandenesch, F., Naimi, T., Enright, M. C., Lina, G., Nimmo, G. R., Heffernan, H., Liassine, N., Bes, M., Greenland, T. \& other authors (2003). Community-acquired methicillin-resistant Staphylococcus aureus carrying Panton-Valentine leukocidin genes: worldwide emergence. Emerg Infect Dis 9, 978-984. 